\title{
DETERMINANTS OF EMOTIONAL LABOUR AMONG EMPLOYEES IN THE HOSPITALITY INDUSTRY IN ACCRA, GHANA
}

\author{
Sarah Blankson-Stiles-Ocran ${ }^{1}$,Eunice Fay Amissah ${ }^{1 *}$, Abigail Opoku Mensah ${ }^{2}$
}

\begin{abstract}
${ }_{1}$ Department of Hospitality and Tourism Management, University of Cape Coast. Ghana, Email: eamissah@ucc.edu.gh
\end{abstract}

${ }_{2}$ Department of Management, School of Business, University of Cape Coast. Ghana.

\begin{abstract}
The purpose of this study was to investigate the determinants of emotional labour among frontline employees in Ghanaian hotels. Specifically, the study identified the determinants of emotional labour which were hypothesized to have significant effects on emotional labour. A total of 205 frontline employees participated in the paper-pencil survey. The questionnaires contained items measuring individual, situational and organisational factors of emotional labour. The results indicated that among the determinants, gender, age and variety of emotional displays had significant effects on emotional labour. These results suggest that gender, age and variety of emotional displays play a critical role in employees' performance of emotional labour in hotels.
\end{abstract}

Key words: Emotional display, affectivity, personality, hotel employees, emotional labour

\section{INTRODUCTION}

Frontline employees in hotels are expected to provide good customer service (Amissah, 2017). However, this often requires emotional labour. This process is defined as the management of emotion and expression in order to conform to organisational rules and expectations (Hochschild, 1983). Such emotional labour consists of maintaining an exciting tone, showing concern and empathy, being friendly and happy as well as suppressing feelings of anger or irritation. Thus, to provide a good service to customers and to act in accordance with these job requirements is the price of professional integration (Andela, Truchot, \& Borteyrou, 2015; Diefendorff, Croyle, \& Gosserand, 2005; Grandey, 2000; Hochschild, 1983). However, due to the affective events occurring in organisations, there are many circumstances in which the emotions felt by employees differ in type and intensity from the prescribed display rules among workers (Andela, Truchot, \& Borteyrou, 2015), especially in hotel operation, resulting in different forms of emotions being displayed. Hotel services are difficult to manage due to certain inherent characteristics such as physical intangibility of the service and inseparability of production and consumption as well as the joint effort of the employee and customer in the delivery of the service) leading to the variability of service encounters (Amenumey, 2007, Amissah, 2014). The intangibility and inseparability elements of the service encounter require some form of employee involvement in the service delivery process (Lashley, 1999, Amissah 2017).

Therefore, frontline employees have to regulate their emotions and their expressions in order to achieve their work goals. Over 30 years of research has unearthed the fact emotional labour can be enormously tasking and under some circumstances, it is detrimental to the well-being of people and organizations (Grandey, Diefendorff, \& Rupp, 2013; Grandey \& Gabriel, 2015; Zou, \& Dahling, 2017). Understanding these personal and situational circumstances that shape the performance and consequences of emotional labour is an important concern for any organization with public-facing employees. Emotional cues are hard to prescribe but stimulating employees to display positive emotions during service interaction is both possible (Li, Carziani \& Barbieri, 2016).

Emotional labour has received some interest in many industries mainly from developed countries. These fields range from adventure 
guides (Sharpe, 2005; Torland, 2013), call centre employees (Zapf et. al., 2003), amusement park employees (Van Maanen \& Kunda, 1989), sales persons (Lee, 2016), 911 dispatchers (Shuler \& Sypher, 2000), police officers (Martin, 1999), construction professionals (Lingard \& Francis, 2005) as well as sports (Lee \& Woo, 2017) health care (Karl \& Peluchette, 2006; Lewis, 2012, Andela, Truchot, \& Borteyrou, 2015) and education (Naring, Briet \& Brouwers, 2006, Lee, Kwon \& Oh (2016). Also Chen, Sun, Lam, Hu, Huo and Zhong (2012), Chu and Murrmann (2006), Igbojekwe (2017), Kim (2008) and Lam and Chen (2012) among others have studied emotional labour in contexts outside the hotel industry in Africa.

Hochschild (1983) suggested three main determinants of emotional labour namely: situational, organisational and individual. However, most studies on determinants of emotional labour (Brotheridge, 2006; Humphrey, Pollack \& Hawver, 2008; Kruml and Geddes 2000; Morris and Feldman 1996; Wilding, Chae \& Jang, 2014) have focused solely on situational factors with very few addressing the individual and organisational determinants (Grandey, 2000; Chen, et. Al., 2012). Thus, relegating individual and organisational factors of emotional labour to the background.

Against this backdrop, the study examines the determinants of emotional labour among frontline employees in the hotel industry. By addressing the aforementioned objective, this study contributes to the global debate on emotional labour specifically the determinants of emotional labour in an African context. It also provides important managerial recommendations, specifically to inform service quality standards that would improve provider-customer interaction and organizational performance.

\section{LITERATURE REVIEW \\ Concept of Emotional labour}

Ashforth and Humphrey (1993) defined emotional labour as an act of expressing desired emotions. While Hochschild (1983) referred to feelings in defining emotional labour, Ashforth and Humphrey (1993) focused on the behavioural aspect of the concept and regarded it as a form of impression management. Like Hochschild (1983), Ashforth and Humphrey (1993) suggested that emotional labour is a consequence of conforming to emotional display rules. Following the interactionist model of emotion, Morris and Feldman's (1996) approach conceptualised emotional labour as the effort, planning, and control required for displaying organizationally desired emotions during service interactions. Morris and Feldman (1996) proposed that emotional labour involves four dimensions, interrelated with each other. These are; a) frequency of appropriate emotional display, b) attentiveness to required display rules, c) variety of emotions to be displayed, and d) emotional dissonance as a result of expressing fake emotions.

\section{The Person-environment Fit Theory}

The person-environmental fit theory developed by French, Kaplan and Van Harrison (1982) emphasizes the match between the characteristics of the individual and the characteristics of the environment. The environment equally represents all the situational and organizational contents and contexts. This model suggests that environmental events are not universal stressors, instead, their stress value depends on perceptions of the individual. These perceptions involve not only cognitive estimates of the demands being made by the environment but also estimates by the individual of his or her competence, capability, personality and motivation to meet those demands. Person jobfit, which is a subset of person-environment fit model suggests that individuals can be protected from stress by two mechanisms. The first is social support and the second is ego defence network (Landy, 1989). Other individual factors that facilitate flexible compatibility between the person and the job include, gender, intelligence, socialization, affectivity, personality type and qualities such as extrovert, introvert, tall and sensory acuity among others (Johnson, 2007). The profound input of Munsterberg (1913) provided meaningful insights into the nature and consequences of human individuality. Munsterberg (1913) found out that an average 
worker possesses some psychological qualities suitable for a particular task and he initially built psychological test to objectively measure and elicit a person's aptitude in important areas. He contends that for organizations to arrive at its efficiency, three things must occur namely, the best possible man the best possible work (i.e. job analysis and contents) and the best possible effect (Haslam, 2004). Generally, this theory proposes that positive responses occur when individuals fit or match the environment. The theory proposes that individual, situational and organisational factors shape emotional labour among employees in the hotel industry.

\section{Forms of Emotional Labour}

There are three different ways of performing emotional labour, such as surface acting, deep acting, and genuine acting or automatic regulation (Ashforth \& Humphrey, 1993; Grandey, 2000; Hochschild, 1983; Morris $\&$ Feldman, 1996). Surface acting is the process of modifying one's expressions, such as putting smiles on a face, without changing their feelings towards a certain display rule. In surface acting, employees need to suppress their felt emotions and fake the required emotions dictated by the display rule. The second strategy is deep acting, which corresponds to the process of trying to change one's feelings required by the display rules. That is, the individual tries to experience the emotion that is appropriate for the situation. Thus, surface acting only manages observable expressions, whereas deep acting attempts to change internal emotional states to meet the organizational expectations (Grandey, 2000). In addition, Ashforth and Humphrey (1993) proposed another category of emotional labour, namely, expression of genuine emotion (genuine acting) or automatic regulation (Zapf, 2002). They argued that previous research has neglected the possibility that employees are able to experience and display appropriate emotions spontaneously. For instance, there is a possibility that hotel employees truly feel sympathetic to a guest in a given situation or naturally have it in them to be hospitable to people, which means it is not necessary for them to engage in surface acting or deep acting. This type of innate expression was labelled emotional labour because it conforms to organizationally required emotions. Diefendorff, Croyle, and Gosserand (2005) confirmed that genuine acting or automatic regulation is a distinct type of emotion regulation performed in an automatic way.

\section{Determinants of Emotional Labour in the Hotel Industry}

Determinants of emotional labour include Situational factors such as expectations of employee's interaction and events that creates an emotional response, individual factors such as demographics and emotion-related characteristics and organizational factors such as social support and employee empowerment through job autonomy. Situational factors related to emotional labour

In the context of emotional labour, the situational factors include the employee's interaction expectation with customers such as frequency, duration, variety and organisational display rules. Drawing on previous emotional labour studies, the variables describing the nature of customer contact and the organization's emotional display rules should contribute to the emotional labour process (Grandey, 2000; Hochschild, 1983; Morris \& Feldman, 1997).

\section{Emotional labour and interaction expectations}

According to Hochschild (1983), certain job characteristics require higher levels of emotional labour from employees. One characteristic is the nature of interaction with customers, in particular, the frequency of contact. To this, Morris and Feldman (1997) added the characteristics of the duration of interactions and variety of emotional expressions. Hochschild's (1983) other proposed characteristics of emotional labour jobs are that the organization expects and controls the emotional expression of the employee. This characteristic can be seen in perceptions of display rules, how much the employees perceive that certain emotional expressions are part of the job. These work role characteristics can be thought of as ongoing situations to which employees respond with emotion regulation 
(Grandey, 2000).

Different work roles hold different expectations for the employee when interacting with customers (Grandey, 2000). Job roles may differ in the frequency that employees are expected to interact with customers. For example, a receptionist at a small hotel may welcome customers once in an hour, but a receptionist at a bigger hotel may meet 10 customers in an hour. Another difference in interactions is the duration demands placed on employees. The work role demands of frequency and duration are situational factors that may increase the likelihood of an employee faking expressions or modifying feelings (Grandey, 2000). Thus, such factors are proposed as causes of emotional labour.

However, no correlations have been found between frequency of interaction and duration with dissonance (Morris \& Feldman, 1997), and between frequency of interactions and surface or deep acting (Grandey, 2000). In another study, frequency of interaction had significant positive relationships with surface acting and deep acting; however, duration was not related to surface or deep acting (Brotheridge \& Lee, 1998). Sohn's (2017) study revealed that there exists a positive effect of variety of interactions on emotional labour. We therefore, propose that:

$H_{1}$ Frequency of interaction has an influence on emotional labour

$\mathrm{H}_{2}$ Duration of interaction has an influence on emotional labour

Emotional display rules refer to the standards that prescribe appropriate display to be expressed on the job (Erol-Korkmaz, 2010) it is assumed to be an important predictor of emotional labour in the literature. Diefendorff, Richard and Croyle (2006) intimated that employees' perceptions of these rules affect their behaviours and expressions of feelings during their interactions with customers. Other researchers have also found a significant positive relationship between perceptions of display rules, and both surface acting and deep acting forms of emotional labour. (Brotheridge \& Grandey, 2002; Grandey, 2003; Rubin et al., 2005; Totterdell and Holman, 2003; and Yang \&
Chang, 2008). However, Diefendorff et al. (2005) found a significant relationship for only surface acting. Based on this, the following hypothesis is proposed:

$\mathrm{H}_{3}$ Emotional display rules have significant effects on emotional labour

An event is appraised for its positive or negative influence on a person's psychological well-being. In particular, if the event interferes with the employees' goals, one of which is to express and induce positive emotions, the event will be appraised negatively (Frijda, 1986; Lazarus, 1991). While negative events are called "hassles", positive events are termed as "uplifts". Hassles are minor events that reflect irritating, frustrating and distressing demands in everyday interactions (Kanner, Coyne, Schafer, \& Lazarus, 1981). On the other hand, uplifts are "minor events that bring joy and happiness" (Basch \& Fisher, 2004). An example of a hassle is a boss yelling at his workers, whereas for uplifts, an example is a recognition from supervisors. Grandey (2000) proposed that affective events may serve as situational cues and influence "employees" emotional labour strategies. According to her, since affective work events have a direct effect on an employee's emotions and influences how he/she feels in a given time, an emotional event may cause more emotional regulation, especially when there is a difference between the emotions evoked by the event and the emotions required by display rules. Studies have linked affective events to "employee" emotions, attitudes and deviant work place behaviour (Erol-Korkmaz, 2010; Judge, Scott \& Ilies, 2006; Keefe \& Bennett, 2006). Thus it is proposed that;

$\mathrm{H}_{4}$ Affective events influence emotional labour

\section{Individual factors related to emotional labour}

According to Grandey (2000), emotion regulation results in physiological arousal that, over the long run, may affect withdrawal behaviours such as leaving the work floor, absenteeism, and turnover. These are outcomes that are of particular concern to customer service jobs, and thus, there are many individual differences that may be related to emotional labour. Grandey 
(2000) further recommends that emotional labour researchers need to integrate personality variables into the emotional labour framework, in order to understand the concept of emotional labour more clearly.

\section{Emotional labour and gender}

A large body of work has been devoted to understanding gender differences in the experience and expression of emotion (Brody \& Hall, 2008, Grandey, 2000; Morris \& Feldman, 1996). Drawing from this literature, it is proposed that gender moderates the individual relationship between frontline employees and the performance of emotional labour, in such a way that the relationship is stronger for females than males. A relatively consistent finding is that women are expected to and do show greater emotional intensity and emotional expressiveness than men, and such differences hold for both positive and negative emotions (Brody \& Hall, 2008).

The root of such differences may lie in role development, whereby females are socialized to be more emotionally expressive and men are socialized to be more emotionally restrained (Brannon, 2016; Grondin, Laflamme, Bienvenue, Labonté \& Roy, 2015; Herrera, Wang, Mather, 2018). Socialization pressures also influence the types of emotions that females and males are expected to express. Positive, relationshipfacilitating emotions such as warmth and cheer are considered more role-appropriate for women than men, whereas negative, distancing emotions such as anger and hostility are viewed as more role-appropriate for men than women (Lindsey 2015; Brody \& Hall, 2008; Simpson \& Stroh, 2004).

Beginning with surface acting, when women attempt to mask or fake an emotion, they should experience greater emotional dissonance because their actions are at odds with their tendency to display and express what they are feeling. Men, however, should experience less emotional dissonance, because they are more accustomed to hiding emotions from others and faking affective states (Wu, Han, \& Mattila, 2016; McDuff, Kodra, el Kaliouby \& LaFrance, 2017). Indeed, Lam, Huo, \& Chen, (2018) found that women were more likely to experience emotional dissonance than men. We therefore propose the following hypothesis;

$\mathrm{H}_{5}$ Gender has a significant effect on emotional labour

\section{Emotional labour and age}

Considering the demographic changes in the workforce and consequently, the increasing number of older individuals seeking employment the in service sector, authors have analysed the impact of age on emotional labour. Age has been found to be positively related to naturally-felt emotions and deep acting while negatively related to surface acting. In fact, according to the socioemotional selectivity theory affective experience and emotional regulation skills are enhanced with maturity. Older individuals realize that life is finite therefore they thrive to develop positive emotions. They develop emotional regulation skills and also learn to suppress negative emotions. Some authors further suggest that mature employees' emotion regulation align with the emotional labour strategy of deep acting(source?). As individuals grow older they accept deep acting as a strategic orientation that is ever more near to naturally expressed emotions. Therefore, the researchers have concluded that older individuals fit well in jobs that require emotional labour because their emotion regulation motivation is intrinsic and during maturation they are able to develop abilities to regulate emotional display effectively (Dahling, and Perez 2010; Johnson, Machowski, Holdsworth, Kern, \& Zapf, 2017). Thus, it is hypothesized that;

$\mathrm{H}_{6}$ Age has a significant effect on emotional labour

\section{Emotional labour and personality}

Beyond demographic variables, there are varieties of related "emotion" variables that have been explored in clinical, developmental, or organizational research. Emotional expressivity as a personality characteristic has been receiving attention lately as a predictor of health and job performance (Walsh, Boehm, \& Lyubomirsky, 2018; Wu, Lu, Chen, \& Xiang, 2018; Newnham, 2017). Recently, a scale on emotional expressivity has been tested by Lee, \& Hyun, (2015). Scale 
on Positive Expressivity, Impulse Intensity, and Masking, seems very related to the ideas of surface acting and deep acting presented earlier. It is likely that persons who are high in positive expressivity, for example, would be skilled at meeting organizational display rules. Thus, such an individual would report lower levels of emotional labour and perform better on service jobs. Expressivity is also related to gender, with women reporting higher levels of emotional expressivity than men (Brannon, 2016; Grondin, Laflamme, Bienvenue, Labonté \& Roy, 2015). From the foregone, it is hypothesized that; $\mathrm{H}_{7}$ Personality type has significant effect on emotional labour

\section{Emotional labour and emotional intelligence}

Another related concept that has been receiving a lot of attention is emotional intelligence (Goleman, 1995; Mayer \& Salovey, 1995). Emotional intelligence is referred to as the ability to recognize and use emotional information in social interactions. Effective affect regulation is one of the signs of strong emotional intelligence (Salovey, Hsee, \& Mayer, 2001). Those with high emotional intelligence are skilled at handling social encounters, and in fact may make other people feel good about themselves (Goleman, 1995). This is a desired characteristic in service encounters. In a study conducted in Malaysia, Hwa and Amin (2016) found a significant relationship between emotional intelligence and emotional labour. Harvey and Dasborough (2006) opined that individuals with high levels of EI exhibit fewer deviant behaviours than those with low levels of EI. Specifically, EI appears to decrease the effects of EL. This lends support for the presence of the buffering effect (Hwa and Amin, 2016; Johnson and Spector, 2007), otherwise known as the "protective effects" (Santos, Mustafa and Terk, 2015) of EI. This affirms the central role of EI in the effective management and performance of emotions among service workers. The following hypothesis is thus formulated:

$\mathrm{H}_{8}$ Emotional intelligence has a significant effect on emotional labour

\section{Emotional labour and affectivity}

Affectivity is the sum of individual mood states (Watson, Clark, \& Tellegen, 1988, Lee and Chelladurai (2015). Austin et al. (2004) opined that affectivity affects the levels and types of emotional labour displayed by service employees. Schaubroeck and Jones (2000, P182) concluded that "the extent to which individuals perceive that they are required to express or suppress certain types of emotional expression may depend as much on their emotional predispositions as it does on the objective characteristics of their organizational role". Affectivity could be positive or negative.

Positive affectivity is related to enthusiasm and optimism, whereas negative affectivity is related to pessimism and aversive mood states. As stated by Weiss and Cropanzano (1996), affective traits act as predispositions toward more or less intense emotional responses. Thus, someone high in negative affectivity (NA) may respond more strongly to negative events if they occur. This means a person with high NA exerts more emotional labour to maintain the emotional display in the face of a difficult encounter. Affectivity has been proposed in theoretical models as a predictor of emotional labour. Morris and Feldman (1996) suggested that positive and negative affectivity would relate to emotional labour. In particular, these researchers hypothesized that when the emotional requirements of a work (express positive or negative emotions) conflicted with affectivity (positive or negative affect), dissonance would occur. Diefendorff et al. (2005) found out that individuals who are higher in positive affectivity have been found to put more effort in changing their inner feelings required by the display rule and thus engage less in surface acting and more in deep acting. According to Lee and Chelladurai (2015), negative affectivity is positively related to surface acting and the relationship between negative affectivity and deep acting, as well as genuine expression. It is therefore hypothesized that;

$H_{9}$ Affectivity has significant effect on emotional labour. 
Organizational Factors Related to Emotional Labour

As suggested by Ashforth and Humphrey (1993) and Morris and Feldman (1996), the environment is a very important factor in understanding emotion management. It is very possible that the situation in which employees work may affect the level and type of emotional labour.

\section{Emotional labour and Social support}

Research findings indicate that social support can alleviate pressures and significantly affect service interactions (Lakey and Cohen, 2000). Previous studies show that physical assistance from colleagues can help employees to improve their work skills (Zhong, Wayne and Liden, 2016). In addition, emotional support gives employees the opportunities to reassess and adjust to stress (Kahn, Schneider, Jenkins-Henkelman, and Moyle, 2006), and to improve performance (Schaufeli and Bakker, 2004). The emotion regulation theory proposed by Wenz-Gross \& Siperstein (1998) considers the environment as a cue to emotional response. Support from coworkers and supervisors should create a positive working environment (Ashkanasy, Zerbe and Hartel, 2016). An employee's perception that he or she works in a supportive climate has been found to relate to job satisfaction, lowered stress, turnover intentions, and team performance (Becker, Cropanzano, Van Wagoner and Keplinger, 2017; Kurtessis, Eisenberger, Ford, Buffardi, Stewart and Adis, 2017; Lyubovnikova, West, Dawson and West, 2018). Indirectly, organisational support may help employees cope with the stress of service jobs. As suggested by Bronder, Speight, Witherspoon and Thomas, (2014) suggested that talking to other people was a method of coping with difficult customers. It is therefore hypothesized that;

H10 Social support has a significant effect on emotional labour

\section{Emotional labour and job autonomy}

Feeling a lack of control over events is a source of stress (Grandey, 2000). Hochschild (1983) discussed the unpleasantness of having an organization control one's personal feelings. A few studies have tested the idea that job autonomy minimizes the stress associated with the emotion regulation process. Wharton (1993) found that those who reported high autonomy had lower emotional exhaustion in both high and low emotional labour-typed jobs. Morris and Feldman (1996) reported that job autonomy was negatively related to emotional dissonance and emotional exhaustion and positively related to job satisfaction. Based on these, we propose the hypothesis below;

\section{METHODOLOGY}

\section{Study Design}

The study followed a cross-sectional survey design and it adopted the positivist philosophy which employs quantitative approaches using self-administered questionnaires. According to Bryman, (2012), a cross-sectional design is a research design that entails the collection of data on more than one case at a single point in time in order to collect a body of quantitative or quantifiable data in connection with two or more variables. The cross-section of design ensures that data was collected from respondents at the same time.

\section{Population}

A total of 205 frontline employees from different upscale hotels in Accra were conveniently sampled to participate in the study. More precisely, 68 employees were from 3-star hotels, 103 employees were from 4-star hotels and 34 were from 5 -star hotels. Front office employees accounted for $48.5 \%$ of the sample, food and beverage employees were $34.5 \%$, housekeeping staff were $7 \%$, and $10.5 \%$ were front office cashiers, sales persons and gift shop attendants. According to Li, Carziani and Barbieri (2016), these different jobs are particularly challenging in terms of emotional demands, as these employees are responsible for providing direct service to customers. Fiftyseven percent were women with majority $(62 \%)$ below 30 years of age. 


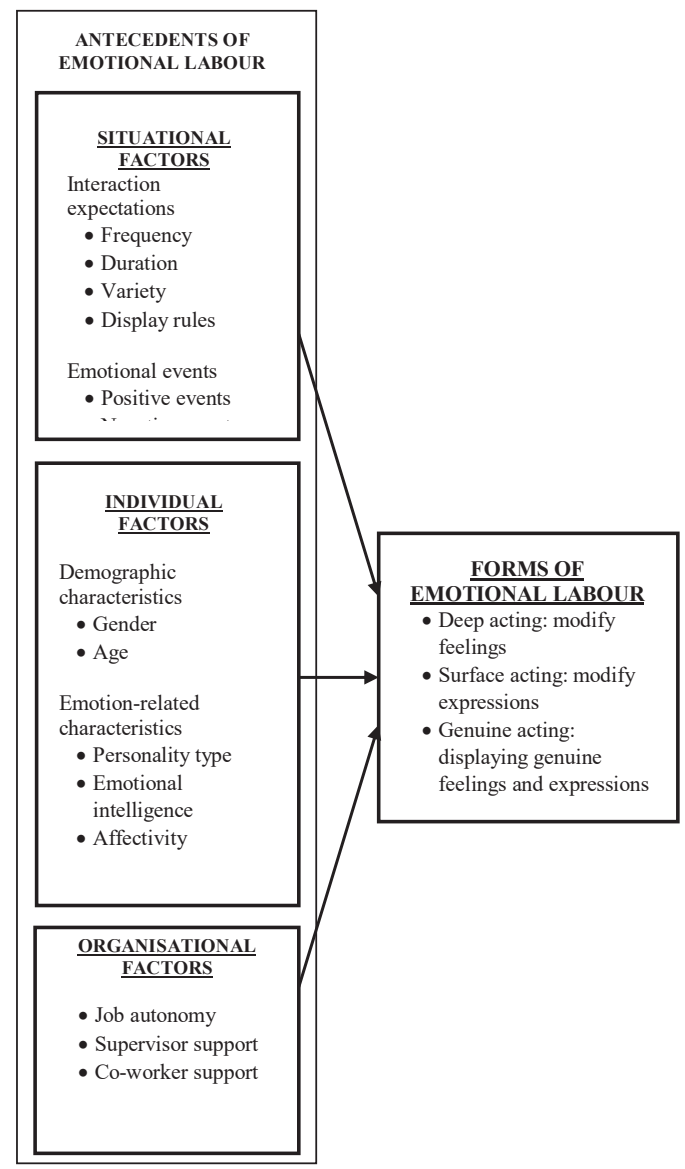

Figure 1: Conceptual Framework of the Determinants of Frontile Employees' Emotional Labour Source: Adapted from Grandy, (2000)

\section{Sample Size and Sampling Procedure}

The study targeted all frontline employees in 3-5 star hotels in Accra. This included front office staff, receptionists, waiters/waitresses and room attendants. A multi-stage sampling technique was employed and in the end 205 employees were selected to participate in the study. Firstly, a list of hotels was obtained from the Ghana Tourism Authority (GTA). Then a reconnaissance survey was conducted to get the total number of frontline staff in all 3-5 star hotels. Secondly, using Krejcie and Morgan's (1970) sample size determination, 310 frontline employees were selected from a total of 580 employees. Thirdly, a disproportionate allocation was assigned to each stratum and finally, a convenient sampling technique was used in selecting frontline hotel employees to participate in the study

\section{Measurement}

The study adopted the 5-point rating scale developed and tested by Brotheridge and Lee, (2003) to measure frequency, duration and variety of interaction as situational factors. Seven items from Diefendorff et al. (2005); adapted from Brotheridge \& Lee (2002), Grandey (2003) and Kruml \& Geddes (2000) were used to assessed surface acting on a 5-point Likert scale (1 strongly disagree; 5 strongly agree). Using the same 5-point Likert scale, four items measured deep acting Similarly, four items from Ashforth and Humphrey (1993) and Zapf (2002) measured genuine acting. The questionnaire also detailed employees' demographic and job characteristics such as age gender, sex, educational background, training and experience in the hospitality industry as well as some working conditions that are vital 
to the study. It also included items on factors that influence the performance of emotional labour. These factors are situational factors, individual factors and organisational factors. The internal consistency reliabilities (Cronbach's alpha) of the scale have been reported as ranged from 0.71 to 0.85 .

\section{Procedure}

Letters seeking permission to undertake the study were sent to the sampled hotels. Arrangements were then made with each hotel for distribution of questionnaires to sampled frontline employees. A return envelope was attached to the questionnaires so that employees could return their completed questionnaires to the human resource managers in the hotels. This was an important element of the survey administration to allay concerns over management reaction to employees' feedback. The researchers went round to collect the envelopes with the complete questionnaires from the HR managers. Out of the 205 desired sample size, 194 representing response rate of $94.6 \%$ were retrieved and used for the study.

\section{Analysis}

The data collected was prepared, processed and analysed using the Statistical Package for Service Solution (SPSS) software version 20. The data was coded and entered into the software, after which editing and scrutiny was done to remove all visible errors, outliers and extreme values that would affect the validity of the results. Standard multiple regression was used to analyse the influence of situational, individual and organisational factors on the emotional labour of hotel frontline employees.

\section{RESULTS \\ Emotional Labour of Employees}

As evident in Table 2, the overall mean values suggest that hotel frontline employees sometimes exhibit surface acting (mean $=2.86)$, but often exhibit deep acting $($ mean $=3.55)$ and genuine acting $($ mean $=3.58)$ in their daily interactions at frontline positions. An examination of this study's results indicate that genuine acting recorded a higher mean score. As such, the respondents utilised genuine acting more than surface acting (mean of 2.86), and slightly higher than deep acting (mean of 3.55). This suggests that genuine acting and deep acting play important roles in the way hotel frontline employees exhibit emotional labour at work.

Table 2: Frequency distribution, mean, and standard deviation of emotional labour

\begin{tabular}{lllllllll}
\hline Forms of Emotional Labour & \multicolumn{9}{c}{ Responses \% (never - Always) } & M & Std. D & Alpha \\
& N & R & S & O & A & & & \\
\hline Deep Acting & 3.7 & 7.2 & 41.8 & 25.8 & 21.6 & 3.55 & 1.023 & $(.843)$ \\
Surface Acting & 19.6 & 14.9 & 35.6 & 19.6 & 10.3 & 2.86 & 1.237 & $(.700)$ \\
Genuine Acting & 5.2 & 4.6 & 41.8 & 23.7 & 24.7 & 3.58 & 1.071 & $(.763)$ \\
Emotional Labour & 4.1 & 7.2 & 47.9 & 28.9 & 11.9 & 3.37 & 0.931 & $(.713)$ \\
\hline
\end{tabular}

\section{Determinants of Emotional Labour}

Table 3 describes the situational, individual and organisational determinants of emotional labour among frontline employees. The items captured as situational determinants include variety of display, frequency of interaction in a day, the duration of interaction per customer and the presence of display rules. Out of the total responses, approximately eighty percent (80\%) interacted with customers and expressed certain emotions towards them whereas about twenty percent $(20 \%)$ rarely or never interacted with customers nor displayed emotions towards guests. The length of interaction was mostly within 5 minutes or less $(83.4 \%)$ with a few interacting between 6-10 minutes (12.9\%). Most employees (65\%) handled 1-60 customers a day with $35 \%$ handling more than 60 customers per day.

Out of the 194 frontline employees who participated in this study, $89.4 \%$ indicated that they were emotionally intelligent and $70 \%$ described their personality types as sanguine. On the issue 
Table 3: Determinants of Emotional Labour ( $N=194)$

\begin{tabular}{|c|c|c|}
\hline Variable & Frequency & $\%$ \\
\hline \multicolumn{3}{|l|}{ Situational factors } \\
\hline \multicolumn{3}{|l|}{ Variety of display } \\
\hline Never & 13 & 6.7 \\
\hline Rarely & 26 & 13.4 \\
\hline Sometimes & 102 & 52.6 \\
\hline Often & 39 & 20.1 \\
\hline Always & 14 & 7.2 \\
\hline \multicolumn{3}{|c|}{ Duration of interaction } \\
\hline $5 \mathrm{~min}$ and below & 162 & 83.4 \\
\hline $6-10 \mathrm{~min}$ & 25 & 12.9 \\
\hline $11-15 \mathrm{~min}$ & 3 & 1.5 \\
\hline $21 \mathrm{~min}$ and above & 4 & 2.1 \\
\hline \multicolumn{3}{|c|}{ Frequency of interaction } \\
\hline $1-60$ & 126 & 65 \\
\hline $61-100$ & 48 & 24.7 \\
\hline Above 100 & 20 & 10.3 \\
\hline \multicolumn{3}{|l|}{ Display rules } \\
\hline Yes & 153 & 79 \\
\hline No & 41 & 21 \\
\hline \multicolumn{3}{|l|}{ Individual factors } \\
\hline \multicolumn{3}{|c|}{ Emotional intelligence } \\
\hline Disagree & 10 & 5.2 \\
\hline Agree & 184 & 94.8 \\
\hline \multicolumn{3}{|l|}{ Personality type } \\
\hline Sanguine & 136 & 70.1 \\
\hline Choleric & 9 & 4.6 \\
\hline Melancholic & 31 & 16.0 \\
\hline Phlegmatic & 18 & 9.3 \\
\hline Affectivity & & \\
\hline
\end{tabular}

\section{Organisational factors}

Co-worker support

$\begin{array}{lcc}\text { Disagree } & 14 & 7.2 \\ \text { Agree } & 180 & 92.8\end{array}$

Supervisory support

$\begin{array}{lcc}\text { Disagree } & 15 & 7.7 \\ \text { Agree } & 179 & 92.3 \\ \text { Job Autonomy } & & \\ \text { Yes } & 64 & 33.0 \\ \text { No } & 130 & 67.0\end{array}$

Effects of Situational, Individual and Organisational Factors on Emotional Labour

Table 4 presents a composite correlation table suggesting that the independent variables are not highly correlated with each other. 
Table 4 Correlation of Composite Variables

\begin{tabular}{|c|c|c|c|c|c|c|c|c|c|c|c|c|}
\hline & 1 & 2 & 3 & 4 & 5 & 6 & 7 & 8 & 9 & 10 & 11 & 12 \\
\hline Emotional Labour & 1 & & & & & & & & & & & \\
\hline Gender & $-.121^{*}$ & 1 & & & & & & & & & & \\
\hline Age in groups & -.055 & $-.154^{*}$ & 1 & & & & & & & & & \\
\hline Educational level & .122 & $.197^{*}$ & -.007 & 1 & & & & & & & & \\
\hline Emotional intelligence & $.162^{*}$ & -.129 & .046 & -.001 & 1 & & & & & & & \\
\hline Personality type & .045 & -.019 & -.001 & -.019 & .041 & 1 & & & & & & \\
\hline customers handled & .056 & .036 & $.148^{*}$ & $.303^{*}$ & .122 & -.073 & 1 & & & & & \\
\hline Length of interaction & -.004 & -.025 & -.089 & -.099 & -.011 & .034 & -.084 & 1 & & & & \\
\hline Frequency of display & $.233^{* *}$ & .083 & .104 & .066 & $.151^{*}$ & .075 & .053 & .011 & 1 & & & \\
\hline Job autonomy & $.167^{*}$ & -.068 & .071 & .022 & $.370^{*}$ & -.006 & .062 & .056 & $.168^{*}$ & 1 & & \\
\hline Co-worker support & $.208^{* *}$ & -.086 & .051 & -.057 & $.507^{*}$ & .027 & .134 & .041 & $.231^{*}$ & $.260^{*}$ & 1 & \\
\hline Supervisory support & $.218^{* *}$ & -.102 & $.169^{*}$ & -.079 & $.502^{*}$ & .039 & .078 & .099 & $.189^{*}$ & $.370^{*}$ & $.562^{*}$ & 1 \\
\hline
\end{tabular}

*significant at 0.05

of social support from co-workers and supervisors, the results as presented in Table 3 suggest that 9 out of 10 employees received emotional support from co-workers and supervisors when they are faced with difficult situations at work. Job autonomy was also considered as an organisational factor and more than half $(67 \%)$ of the respondents were not given autonomy at work regarding how they approach given situations as they emanate from their interaction with customers.

Further, the results for the regression analysis test is presented in Table 5 and captures the VIF values above 1 and tolerance values below 1 suggesting the assumptions of normality and linearity are not violated. Also, the maximum Cooks value (0.055) for the model was below 1 suggesting no cause for concern or a violation of the normality assumption.

Table 5: Standard Multiple Regression on Factors Influencing Emotional Labour

\begin{tabular}{lcccccc}
\hline Variable & Beta & $\mathrm{t}$ & Sig. & $\begin{array}{c}\text { Part } \\
\text { correlation }\end{array}$ & Tolerance & VIF \\
\hline Gender (female $=1)$ & & & & & \\
Age & -.173 & -2.381 & .018 & -.164 & .905 & 1.105 \\
Emotional Intelligence & -.153 & -1.964 &. $\mathbf{0 5 1}$ & -.136 & .784 & 1.275 \\
Positive Affectivity & -.083 & -.940 & .348 & -.065 & .610 & 1.639 \\
Negative Affectivity & -.123 & -1.633 & .104 & -.113 & .838 & 1.193 \\
Personality type & -.056 & -.777 & .438 & -.054 & .922 & 1.085 \\
Level of education & .051 & .719 & .473 & .050 & .949 & 1.054 \\
Frontline job categories & .125 & 1.639 & .103 & .113 & .824 & 1.213 \\
Training in hospitality & .035 & .463 & .644 & .032 & .847 & 1.181 \\
variety of display & -.020 & -.265 & .791 & -.018 & .865 & 1.156 \\
Number of customers handled & .229 & 3.071 & .002 & .212 & .858 & 1.166 \\
Length of interaction & .027 & .341 & .734 & .024 & .770 & 1.299 \\
Display rules & -.018 & -.254 & .800 & -.018 & .924 & 1.083 \\
Job autonomy & .013 & .169 & .866 & .012 & .857 & 1.167 \\
Co-worker support & .076 & 1.049 & .296 & .072 & .902 & 1.109 \\
Supervisor support & .075 & .910 & .364 & .063 & .699 & 1.430 \\
\hline
\end{tabular}


The overall regression model was found to be significant $(\mathrm{F}(15,177)=2.035, \mathrm{p}<0.05)$, with an R2 $=0.147$ which suggests that individual, situational and organisational factors contribute $14.7 \%$ of the total variance explained in emotional labour of hotel frontline employees. Out of the total variance explained in emotional labour, only three variables (age, gender and variety of display) made significant contributions. The contributions of the individual, situational and organizational factors are discussed below.

\section{Individual factors}

The findings of this study suggest a statistically significant inverse effect of gender (beta $=-0.173, \mathrm{t}=-2.381, \mathrm{p}>0.05$ ) on emotional labour in that women are more likely to exhibit emotional labour at the workplace from their male counterparts. The other individual factor that significantly accounted for emotional labour was age (beta $=-0.153, \mathrm{t}=-1.964, \mathrm{p}<0.05$ ). However, the beta is negated, which suggest an inverse relation such that younger frontline employees are more likely to exhibit emotional labour.

Table 4 also shows that there is no significant effect of the emotion-related characteristics [emotional intelligence (beta $=$ $-0.083, \mathrm{t}=-0.940, \mathrm{p}>0.05)$; positive affectivity (beta $=-0.123, \mathrm{t}=-1.633, \mathrm{p}>0.05)$; negative affectivity (beta $=-0.056, \mathrm{t}=-0.777, \mathrm{p}>0.05$ ) and personality type (beta $=0.051, \mathrm{t}=0.719$, $\mathrm{p}<0.05)$ ] on emotional labour although literature suggests there exist some form of relationship between these emotion-related characteristics and emotional labour (Chu et, al. 2012; Lee \& Ok, 2014).

\section{Situational factors}

Grandey (2000) proposes that variety of display, frequency of interaction and duration of interaction as well as the presence of emotional display rules are the situational factors that influence frontline employees' emotional labour. The results however suggest that, out of the situational factors mentioned above, only variety of display made a statistically significant contribution to the variance in emotional labour (beta $=0.229, \mathrm{t}=3.071, \mathrm{p}=<0.05$ ). The beta and t-values are positive which suggest a direct relationship between the variety of emotional display and emotional labour in that the higher the variety of emotional display, the higher the emotional labour of hotel frontline employees and vice versa.

\section{Organisational factors}

The results as presented in Table 5 suggest that there is no statistically significant effect of organisational factors (job autonomy, co-worker support and supervisory support) on emotional labour. However, the literature suggests a relationship between organisational support and emotional labour (Lam and Chen, 2012; Shani, Uriely, Reichel, and Ginsburg 2014).

\section{DISCUSSION AND CONCLUSION}

It is concluded that males are less able to manage their feelings as opposed to their female counterparts. Bolton (2005) and Hochschild (2003) argue that gender is an issue with regards to emotional labour since most service jobs are performed by women whose association with using feelings and emotions at work and in the home goes back to the gendered division of labour that emerged because of capitalism. This finding is supported by the empirical review of Schaubroeck and Jones (2000) who conducted a study on workers' perceptions of the extent to which they performed emotional labour. Schaubroeck and Jones (2000) found a higher prevalence of perceived emotional labour amongst women. It is therefore assumed that females by their nature are more emotionally empathic than their male counterparts. This assertion is affirmed by Grandey (2000) that men and women have different motives for regulating emotions, in that women are more concerned with getting along, whereas men are more motivated to stay in control and express powerful emotions such as anger or pride. However, in the customer service setting, this motive may not work in men's favour. It is therefore possible that men may need more training to manage emotions when dealing with customers.

The conventional logic is that older people 
are rather better at managing their emotions. However, younger employees were found to be better at managing emotions as compared to the older ones. Meanwhile, literature confirms the effect of age on emotional labour. Dahling and Perez (2010) suggest a direct effect of age on emotional labour in that, the younger employees are the less likely to manage their emotions whereas older people are more likely to manage their emotions whilst at work. This conclusion was drawn by the researchers because according to them, older people fit well in jobs that require emotional labour because their emotional regulation motivation is intrinsic and that during maturity they develop abilities to regulate emotions effectively. The findings of this study could be attributed to the fact that frontline positions in the hotel industry are dominated by younger people who are trained either in schools or onthe-job as to how to relate to guests so they are able to adjust themselves to suit the display rules of the hotels.

Dealing with a lot of people with varied emotional needs and concerns will require employees to manage their emotions more frequently to suit specific situations. As a result, variety of emotional display was found to positively influence the emotional labour of frontline hotel employees. This finding is consistent with Sohn's (2017) finding that there exists a positive effect of variety of interactions on emotional labour. The results may also be justified by the fact that when hotel frontline employees interact with more customers over time, they express varied emotions especially within short intervals. For instance, front desk employees will experience both positive and negative emotions like anger, happiness, frustration, optimism and hostility among others when checking in group guests. This is due to the fact that customers differ in their expectations, behaviour and attitudes. Employees are therefore forced to manage their expressions to suit the situation they deal with. As a result, the higher the variety of display, the higher the emotional labour and the lower the variety of display, the lower the emotional labour of hotel frontline employees.

Emotional intelligence is therefore considered a desirable trait in service delivery (Goleman, 1995). This may be due to the fact that positive emotions expressed towards guests yield customer satisfaction and possibly encourages repeat visits for the hotels. Li, Canziani and Barbieri (2016) back this assertion by indicating that hospitality employees' emotional displays are critical for branding, as well as for repeat business and increased profitability. Though there is no significant effect of the emotionrelated characteristics on emotional labour, most employees purported to be emotionally intelligent. The literature suggests that employees with high emotional intelligence are skilled at handling social encounters and may make others feel good about themselves. The theory of Person-Job-Fit suggests that personality type plays a crucial role in the relationship between emotional labour and psychological well-being. Employees who are enthusiastic, active, always happy and social are classified as being sanguine. Such employees do not easily get irritated when they face difficult situations at work as such they face lesser stress during their daily interactions with guests at the frontline. Being sanguine is a desirable trait in the hospitality industry as it facilitates the flexible compatibility between the person and the hotel job (Johnson, 2007). The study reaffirms the positive emphasis of the job-person fit theory which posits that individual factors that facilitate flexible compatibility between a person and her/his job include, gender, age, intelligence, socialization, affectivity and personality type. Generally, this theory proposes that positive responses occur when individuals fit or match the environment. This has noteworthy managerial implications in terms of selection, hiring, and training policies and practices in the hotel industry.

\section{Study Limitations and Future Research}

Results of this study should be interpreted with caution given three main limitations. First, the cross-sectional nature of the study which allowed for the collection of data at a single point in time may not reveal how these determinants influence emotional labour over a period of time. Therefore, future studies should adopt a longitudinal approach. Secondly, spatially, the 
study was limited to only upscale hotels in the Accra Metropolis as such the findings cannot be generalized for the entire hotel industry in Ghana. It is suggested that future studies consider replicating this on a larger scale (sample size) and wider scope (all categories of hotels) in the country. Finally, contextual issues were not captured due to the quantitative methods employed in the study. It is therefore, recommended that future studies incorporate both quantitative and qualitative methods.

\section{REFERENCES}

Amenumey, E. K. (2007). Psychological Climate, Psychological Empowerment and Empowered Behaviour: A study of a Luxury Hotel Group. Unpublished Thesis presented to the School of Management, University of Surrey

Amissah, E. F. (2014). Customers' perceptions of service quality in hotels, Ghana. Oguaa Journal of Social Sciences, 7, 100-125

Amissah, E. F. (2017). Stakeholders' perceptions of service quality in hotels, Journal of Arts and Social Sciences, 8, 36-55

Andela, M., Truchot, D. and Borteyrou, X. (2015). Emotional labour and burnout: Some methodological considerations and refinements. Canadian Journal of Behavioural Science, 47(4), 321-332. http://dx.doi.org/10.1037/cbs0000024

Ashforth, B. E., \& Humphrey, R. H. (1993). Emotional labour in service roles: The influence of identity. Academy of Management Review, 18(1), 88-115.

Ashkanasy, N. M., Zerbe, W. J., \& Hartel, C. E. (2016). Managing Emotions in the Workplace. Routledge.
Austin E.J., Saklofske D.H., Huang S.H., McKenney D. (2004). Measurement of trait emotional intelligence: Testing and crossvalidating a modified version of Schutte et al.'s (1998) measure. Personality and Individual Differences, 36(3), 555-562

Basch, J., \& Fisher, C. D. (2004). Development and validation of measures of hassles and uplifts at work. In Annual Meeting of the Academy of Management.

Becker, W. J., Cropanzano, R., Van Wagoner, P., \& Keplinger, K. (2017). Emotional labour within teams: Outcomes of individual and peer emotional labour on perceived team support, extra-role behaviors, and turnover intentions. Group \& Organization Management, 1059601117707608.

Bronder, E. C., Speight, S. L., Witherspoon, K. M., \& Thomas, A. J. (2014). John Henryism, depression, and perceived social support in Black women. Journal of Black Psychology, 40(2), 115-137.

Brannon, L. (2016). Gender: Psychological Perspectives. Taylor \& Francis.

Brody, L. R., \& Hall, J. A. (2008). Gender and emotion in context. Handbook of emotions, 3, 395-408.

Brotheridge, C. M. (2006). A review of emotional labour and its nomological network: practical and research implications. Ergonomia, 28 (4), 295-309

Brotheridge, C. M., \& Grandey, A. A. (2002). Emotional labour and burnout: Comparing two perspectives of "people work". Journal of Vocational Behavior, 60(1), 17-39. 
Brotheridge, C. M., \& Lee, R. T. (2003). Development and validation of the emotional labour scale. Journal of Occupational and Organizational Psychology, 76(3), 365-379.

Bryman, A. (2012), Social Research Methods, 4th edn, Oxford University Press, New York.

Chen, Z., Sun, H., Lam, W., Hu, Q., Huo, Y., \& Zhong, J. A. (2012). Chinese hotel employees in the smiling masks: Roles of job satisfaction, burnout, and supervisory support in relationships between emotional labour and performance. The International Journal of Human Resource Management, 23(4), 826-845.

Chu, K. H, Baker, M. A. \& Murrmann, S. S. (2012). When we are onstage, we smile: The effects of emotional labour on employee work outcomes. International Journal of Hospitality Management, 31(3), 906-915

Chu, K. H. L., \& Murrmann, S. K. (2006). Development and validation of the hospitality emotional labour scale. Tourism Management, 27(6), 1181-1191.

Dahling, J. J., \& Perez, L. A. (2010). Older worker, different actor? Linking age and emotional labour strategies. Personality and Individual Differences, 48(5), 574578.

Diefendorff, J. M., Croyle, M. H., \& Gosserand, R. H. (2005). The dimensionality and antecedents of emotional labour strategies. Journal of Vocational Behavior, 66(2), 339-357.

Diefendorff, J. M., Richard, E. M., \& Croyle, M. H. (2006). Are emotional display rules formal job requirements? Examination of employee and supervisor perceptions. Journal of Occupational and
Organizational Psychology, 79(2), 273298.

Erol-Korkmaz, H. T. (2010). The relationship of categories of work events to affective states and attitudes in the workplace: A test of the affective events theory. Unpublished doctoral dissertation). Middle East Technical University, Ankara, Turkey.

French, J. R., Caplan, R. D., \& Van Harrison, R. (1982). The Mechanisms of Job Stress and Strain (Vol. 7). Chichester [Sussex]; New York: J. Wiley.

Frijda, N. H. (1986). The Emotions. CambridgeUniversity Press

Goleman, D. (1995). Emotional intelligence: Why it can matter more than IQ for character, health and life long Achievement. Bantam Books: New York.

Grandey, A. A. (2000). Emotional regulation in the workplace: A new way to conceptualize emotional labour. Journal of Occupational Health Psychology, 5(1), 95.

Grandey, A. A. (2003). When "the show must go on": Surface acting and deep acting as determinants of emotional exhaustion and peer-rated service delivery. Academy of Management Journal, 46(1), 86-96.

Grandey, A. A., Diefendorff, J. M., \& Rupp, D. E. (2013). Bringing emotional labour into focus: A review and integration of three research lenses. In A. A. Grandey, J. M. Diefendorff, \& D. E. Rupp (Eds.), Emotional labour in the 21st century (pp. 3-27). New York, NY: Routledge.

Grandey, A. A., \& Gabriel, A. S. (2015). Emotional labour at a crossroads: Where do we go from here? Annual Review of Organizational Psychology and Organizational Behavior, 2, 323-349. 
Grondin, S., Laflamme, V., Bienvenue, P., Labonté, K., \& Roy, M. L. (2015). Sex effect in the temporal perception of faces expressing anger and shame. International Journal of Comparative Psychology, 28. Retrieved from: http://escholarship.org/ uc/item/8vx215m0.

Harvey P., \& Dasborough, M. T. (2006). Consequences of employee attributions in the workplace: The role of emotional intelligence. Psicothema, 18, 145-151.

Haslam, S. A. (2004). Psychology in Organizations. Sage.

Herrera, A. Y., Wang, J., \& Mather, M. (2018). The gist and details of sex differences in cognition and the brain: How parallels in sex differences across domains are shaped by the locus coeruleus and catecholamine systems. Progress in neurobiology health psychology, 12(2), 177.

Hochschild, A. R. (1983). The Managed Heart. Berkeley and Los Angeles.

Humphrey, R. H., Pollack, J. M., \& Hawver, T. (2008). Leading with emotional labour. Journal of managerial psychology, 23(2), 151-168.

Hwa, M. A. C. \& Amin, H. (2016). Why emotion at work matters: Examining the influence of emotional labour and emotional intelligence and workplace behaviours among service workers in East Malaysia. Kajian Malaysia, 34(1), 79-105.

Igbojekwe, P. (2017). Impacts of emotional labour on employee job performance in hotels in south east, Nigeria. IJAR, 3(7), 943-953.

Johnson, H. A. M. (2007). Service with a smile: Antecedents and consequences of emotional labour strategies, Doctoral dissertation, University of South Florida.
Johnson, H. A. M., \& Spector, P. E. (2007). Service with a smile: Do emotional intelligence, gender, and autonomy moderate the emotional labour process? Journal of Occupational Health Psychology, 12(4), 319.

Johnson, S. J., Machowski, S., Holdsworth, L., Kern, M., \& Zapf, D. (2017). Journal of Work and Organizational Psychology. Revista de Psicología del Trabajoy de las Organizaciones, 33(3), 205-216.

Judge, T. A., Scott, B. A., \& Ilies, R. (2006). Hostility, job attitudes, and workplace deviance: test of a multilevel model. Journal of Applied Psychology, 91(1), 126.

Kahn, J. H., Schneider, K. T., Jenkins-Henkelman, T. M., \& Moyle, L. L. (2006). Emotional social support and job burnout among high-school teachers: is it all due to dispositional affectivity? Journal of Organizational Behavior, 27(6), 793-807.

Kanner, A. D., Coyne, J. C., Schaefer, C., \& Lazarus, R. S. (1981). Comparison of two modes of stress measurement: Daily hassles and uplifts versus major life events. Journal of behavioral medicine, 4(1), 1-39.

Karl, K. A., \& Peluchette, J. V. (2006). Does workplace fun buffer the impact of emotional exhaustion on job dissatisfaction? A study of health care workers. Journal of Behavioral and Applied Management, 7(2), 128

Keeffe, D. A. \& Bennett, R. R. (2006). An Investigation of Functional and Dysfunctional Consumer Behaviour during Frontline Service Encounters, Paper presented to Queensland University of Technology 
Kim, H. J. (2008). Hotel service providers' emotional labour: the antecedents and effects on burnout. International Journal of Hospitality Management, 27 (2),151161.

Krejcie, R. V. and Morgan, D. W. (1970). Determining sample size for research activities. Educational and Psychological Measurement, 30, 607-10.

Kruml, S.M. and Geddes, D. (2000). Exploring the dimensions of emotional labour: The heart of Hochschild's work. Management Communication Quarterly, 14(1): 8-49.

Kurtessis, J. N., Eisenberger, R., Ford, M. T., Buffardi, L. C., Stewart, K. A., \& Adis, C. S. (2017). Perceived organizational support: A meta-analytic evaluation of organizational support theory. Journal of Management, 43(6), 1854-1884.

Lakey, B. \& Cohen, S., 2000. Social support theory and measurement. In: Cohen, S., Underwood, L.G., Gottlieb, B. (Eds.), Social Support Measurement and Intervention: A Guide for Health and Social Scientists. Oxford University Press, Toronto, pp. 29pp.

Lam, W., \& Chen, Z. (2012). When I put on my service mask: Determinants and outcomes of emotional labour among hotel service providers according to affective event theory. International Journal of Hospitality Management, 31(1), 3-11.

Lam, W., Huo, Y., \& Chen, Z. (2018). Who is fit to serve? Person-job/organization fit, emotional labour, and customer service performance. Human Resource Management, 57(2), 483-497.

Landy, F. J. (1989). Psychology of Work Behaviour. Thomson Brooks/Cole Publishing Co.
Lashley, C. (1999). Employee empowerment in services: a framework for analysis, Personnel Review, 28(3), 169-91.

Lazarus, R. S. (1991). Cognition and motivation in emotion. American psychologist, 46(4), 352.

Lee, Y. H., Chelladurai, P., \& Kim, Y. (2015). Emotional labour in sports coaching: Development of a model. International Journal of Sports Science \& Coaching, 10(2-3), 561-575 DOI: 10.1080/10413200.2015.1092481

Lee, O. H. (2016). The effect of emotional labour, emotional exhaustion, and depression on job-related attitudes of fashion store salespersons. Fashion business, 20(1), 69-81.

Lee, K. H., \& Hyun, S. S. (2015). A model of behavioural intentions to follow online travel advice based on social and emotional loneliness scales in the context of online travel communities: The moderating role of emotional expressivity. Tourism Management, 48, 426-438.

Lee, Y. H., Kwon, H. H. \& Oh, H. (2016). Emotional labour in teaching secondary physical education. International Journal of Kinesiology \& Sports Science, 4 (2), $1-10$.

Lee, J. J. \& Ok, C. (2012). Reducing burnout and enhancing job satisfaction: Critical role of hotel employees' emotional intelligence and emotional labour. International Journal of Hospitality Management, 31(4), 1101-1112.

Lee, Y. H., \& Woo, B. (2017). Emotional intelligence, emotional labour, and emotional exhaustion among Korean fitness employees. Journal of Global Sport Management, 2(1), 65-78. 
Lewis, L. (2012). It's people's whole lives': Gender, class and the emotion work of user involvement in mental health services. Gender, Work and Organization. 19 (3), 276-305. doi:10.1 111/j.1468-0432.2009.00504.xg

Li, Canziani \& Barbieri (2016). Emotional labour in hospitality: Positive affective displays in service encounters. Tourism and Hospitality Research, 18(2), 242-253. DOI: $10.1177 / 1467358416637253$

Lindsey, L. L. (2015). Gender roles: A sociological perspective. Routledge.

Lingard H. \& Francis V. (2005). Does work-family conflict mediates the relationship between Job schedule demands and Burnout in male construction professionals and managers? Construction Management \& Economics, 23, 733-745.

Lyubovnikova, J., West, T. H., Dawson, J. F., \& West, M. A. (2018). Examining the indirect effects of perceived organizational support for teamwork training on acute health care team productivity and innovation: The role of shared objectives. Group \& Organization Management, 43(3), 382413.

Martin, S. E., (1999). Police force or police service? Gender and emotional labour. The Annals of the American Academy of Political and Social Science, 561(1), 111126. doi: 10.1177/000271629956100108

Mayer, J. D., \& Salovey, P. (1995). Emotional intelligence and the construction and regulation of feelings. Applied and preventive psychology, 4(3), 197-208.

McDuff, D., Kodra, E., el Kaliouby, R., \& LaFrance, M. (2017). A large-scale analysis of sex differences in facial expressions. PloS one, 12(4), e 0173942.
Morris, J. A., \& Feldman, D. C. (1997). Managing emotions in the workplace. Journal of Managerial Issues, 257-274.

Munsterberg, H. (1913). Psychology and industrial efficiency. New York: Houghton-Mifflin.

Näring, G., Briët, M., \& Brouwers, A. (2006). Beyond demand-control: Emotional labour and symptoms of burnout in teachers. Work \& Stress, 20(4), 303-315.

Newnham, M. P. (2017). A comparison of the enactment and consequences of emotional labour between frontline hotel workers in two contrasting societal cultures. Journal of Human Resources in Hospitality \& Tourism, 16(2), 192-214.

Rubin, R. S., Munz, D. C., \& Bommer, W. H. (2005). Leading from within: The effects of emotion recognition and personality on transformational leadership behavior. Academy of Management Journal, 48(5), 845-858.

Salovey, P., Hsee, C. K., \& Mayer, J. D. (2001). Emotional intelligence and the selfregulation of affect. Emotions in social psychology: Essential readings (pp. 185197). Philadelphia, PA: Psychology Press.

Schaubroeck, J., \& Jones, J. R. (2000). Antecedents of workplace emotional labour dimensions and moderators of their effects on physical symptoms. Journal of Organizational Behavior, 163-183.

Schaufeli, W. B., \& Bakker, A. B. (2004). Job demands, job resources, and their relationship with burnout and engagement: A multi-sample study. Journal of organizational Behavior, 25(3), 293-315. 
Shani, A., Uriely, N., Reichel, A., \& Ginsburg, L. (2014). Emotional labour in the hospitality industry: The influence of contextual factors. International Journal of Hospitality Management, 37, 150-158.

Sharpe, E. K. (2005). Going above and beyond: the emotional labour of adventure guides. Journal of Leisure Research, 37(1), 29-50.

Shuler, S. \& Sypher, B. D. (2000). Seeking emotional labour: When managing the heart enhances the work experience. Management Communication Quarterly, 14, 50-89.

Sohn, H. K. (2017). Verifying the moderating effects of personality factors on the relationship between emotional labour and customer orientation. International Journal of Tourism Sciences, 17(1), 1-14.

Simpson, P. A., \& Stroh, L. K. (2004). Gender differences: Emotional expression and feelings of personal inauthenticity. Journal of Applied Psychology, 89, 715-721.

Torland, M (2013). Emotional labour and the job satisfaction of adventure tour leaders in Australia, Unpublished PhD thesis, Southern Cross University, Lismore, NSW.

Totterdell, P., \& Holman, D. (2003). Emotion regulation in customer service roles: Testing a model of emotional labour. Journal of Occupational Health Psychology, 8(1), 55.

Van Maanen, J., \& Kunda, G. (1989). Real feelings. Emotional expression and organizational culture, in LL. Cummings, BM. Staw (eds.), Research in Organizational Behaviour (vol. 11).
Walsh, L. C., Boehm, J. K., \& Lyubomirsky, S. (2018). Does happiness promote career success? Revisiting the evidence. Journal of Career Assessment, 26(2), 199-219. https://doi.org/10.1177/1069072717 751441.

Watson, D., Clark, L. A., \& Tellegen, A. (1988). Development and validation of brief measures of positive and negative affect: the PANAS scales. Journal of personality and social psychology, 54(6), 1063-1076.

Weiss, H. M., \& Cropanzano, R. (1996). Affective events theory: A theoretical discussion of the structure, causes and consequences of affective experiences at work. Research in Organizational Behavior: An Annual Series of Analytical Essays and Critical Reviews, (Vol. 18).

Wenz-Gross, M., \& Siperstein, G. N. (1998). Students with learning problems at risk in middle school: Stress, social support, and adjustment. Exceptional Children, 65(1), 91-100.

Wharton, A. S. (1993). The affective consequences of service work: Managing emotions on the job. Work and occupations, 20(2), 205-232.

Wilding, M., Chae, K., \& Jang, J. (2014). Emotional labour in Korean local government: Testing the consequences of situational factors and emotional dissonance. Public Performance \& Management Review, 38(2), 316-336.

Wu, L., Han, R., \& Mattila, A. S. (2016). A double whammy effect of ethnicity and gender on consumer responses to management level service failures. Journal of Service Management, 27(3), 339-359. 
Wu, Y., Lu, J., Chen, N., \& Xiang, B. (2018). The influence of extraversion on emotional expression: A moderated mediation model. Social Behavior and Personality: an international journal, 46(4), 641-652.

Yang, F. H., \& Chang, C. C. (2008). Emotional labour, job satisfaction and organizational commitment amongst clinical nurses: A questionnaire survey. International Journal of Nursing Studies, 45(6), 879887.

Zapf, D. (2002). Emotion work and psychological well-being: A review of the literature and some conceptual considerations. Human Resource Management Review, 12, 237 -268 .

Zapf, D., Isic, A., Bechtoldt, M., \& Blau, P. (2003). What is typical for call centre jobs? Job characteristics, and service interactions in different call centres. European Journal of Work and Organizational Psychology, 12(4), 311-340
Zapf, D. \& Holz, M. (2006). On the positive and negative effects of emotion work in organizations. European Journal of Work and Organizational Psychology, 15, 1- 28.

Zhong, L., Wayne, S. J., \& Liden, R. C. (2016). Job-engagement, perceived organizational support, high-performance human resource practices, and cultural value orientations: A cross-level investigation. Journal of Organizational Behavior, 37(6), 823-844.

Zou, W. \& Dahling, J. (2017). Workplace spirituality buffers the effects of emotional labour on employee well-being, European Journal of Work and Organizational Psychology, 26 (5), 769-777, DOI: 10.1080/1359432X.2017.1358164 